\title{
Hydrogen Distribution in Carbon and Silicon Specimens Studied by the Scanning Atom Probe
}

\author{
O. Nishikawa, T. Murakami, M. Watanabe, and M. Taniguchi \\ Kanazawa Institute of Technology, 7-1 Ohgigaoka, Nonoichi, Ishikawa 921-8501 Japan \\ nisikawa@neptune.kanazawa-it.ac.jp
}

It has been known that the atom probe (AP) [1] is one of the most powerful instrument to detect the hydrogen atoms bound with other atoms such as aluminum and copper [2]. However, it has been also realized that the study of carbon and silicon is hardly investigated because the fabrication of a sharp silicon and carbon tip required for the AP analysis is fairly difficult. The introduction of a scanning atom probe (SAP) [3] made possible to mass analyze a flat specimen with microprotrusions. Accordingly, the study has been extended to carbon and silicon counting the number of hydrogen atoms absorbed in these materials. Thus, the purpose of this study is to examine the relation among the structures of carbon specimens and to clarify the effect of chemical treatment of silicon.

Graphite, vitreous carbon, CVD diamond, HPHT diamond and carbon nano-tubes (CNT) were analyzed. The purities of the graphite are $99.8 \%$ and $99.99 \%$. One of the CNT is the bunch of multi-wall carbon nano-tubes (MWCNT) and other is rod shaped CNT made from a mixture of $\mathrm{C}_{60}$ and CNT [4].

Silicon specimens were fabricated by grooving a [111]-oriented silicon wafer surface in a checker board pattern forming silicon micro pyramid arrays. The depth and the width of the grooves are 10 $\mu \mathrm{m}$ and $100 \mu \mathrm{m}$, respectively. The grooved specimens are etched by $1 \% \mathrm{HF}$ and $40 \% \mathrm{NH}_{4} \mathrm{~F}$ [5].

The number of hydrogen atoms in the carbon and silicon specimens is counted by dividing the mass to charge ratio $\mathrm{m} / \mathrm{n}$ into 0.1 sections and assigning each ion, Fig. 1 . Although the mass spectrum is continuous due to the dissociation of $\mathrm{C}-\mathrm{H}$ cluster, each divided mass peaks are assigned. The $\mathrm{m} / \mathrm{n}$ of $\mathrm{C}_{5}{ }^{+}$is 60 and the right side of this peak is formed by the dissociated $\mathrm{C}_{5} \mathrm{H}^{+}, \mathrm{C}_{5} \mathrm{H}_{2}{ }^{+}$and so on. The ions with the $\mathrm{m} / \mathrm{n}$ smaller than 60 are the dissociated hydrogen after reflected in the reflectron.

All carbon specimens contain a large amount of hydrogen. The ratio of hydrogen atoms to carbon atoms $\mathrm{H} / \mathrm{C}$ of various carbon specimens are listed in Table 1. Vitreous carbon contains the smallest amount of hydrogen and $\mathrm{H} / \mathrm{C}=0.25$. The number of hydrogen atoms in the surface layers of the CVD diamond grown in hydrogen gas contains the largest amount of hydrogen, $\mathrm{H} / \mathrm{C}=2.02$.

$\mathrm{CNT}$ exhibits the moderate $\mathrm{H} / \mathrm{C}$ values in the range of 0.283 to 0.721 . Although the amount of hydrogen absorbed in the MWCNT does not change by the heating at $1000 \mathrm{~K}$ for $10 \mathrm{~min}$, a large amount of hydrogen is desorbed from the CNT rod by storing it in a vacuum chamber.

The amount of hydrogen atoms in silicon varies with the analyzed areas. While a small number of hydrogen atoms were detected from a few silicon surface areas, Fig. 2, a large amount of hydrogen is detected with carbon and oxygen from other areas of the same specimen, Fig. 3. Variation of hydrogen, carbon and oxygen with depth is listed in Table 2 and 3. Difference in the hydrogen and oxygen contents may due to the difference in the exposed crystal plane of the analyzed area formed by the grooving.

[1] E. W. Müller and S.V. Krishnaswamy, Rev. Sci. Instrum., 39 (1968) 83.

[2] O. Nishikawa, T. Yoshimura and M. Shibata, Surf. Sci., 124 (1983) 440.

[3] O. Nishikawa, Y. Ohtani, K. Maeda, M. Watanabe, and K. Tanaka, Mater. Character. 44 (2000) 
29.

[4] T. Kuzumaki, Y. Takamura, H. Ichinose, and Y. Horie, Appl. Phys. Lett., 78 (2001) 3699.

[5] Y. Morita, K. Miki, and H. Tokumoto, Mat. Res. Soc. Sym. Proc., 315 (1993) 491.

Table $1 . \mathrm{H} / \mathrm{C}$ of various carbon

\begin{tabular}{|l|l|}
\hline Specimen & $\mathrm{H} / \mathrm{C}$ \\
\hline Fresh CNT rod & 0.541 \\
\hline CNT rod 40 hrs later & 0.283 \\
\hline MWCNT & 0.714 \\
\hline Heated MWCNT & 0.714 \\
\hline 99.99 \% pure graphite & 0.442 \\
\hline Vitreous carbon & 0.249 \\
\hline CVD diamond & 1.277 \\
\hline HF-CVD diamond & 2.018 \\
\hline HPHT diamond & 0.857 \\
\hline
\end{tabular}

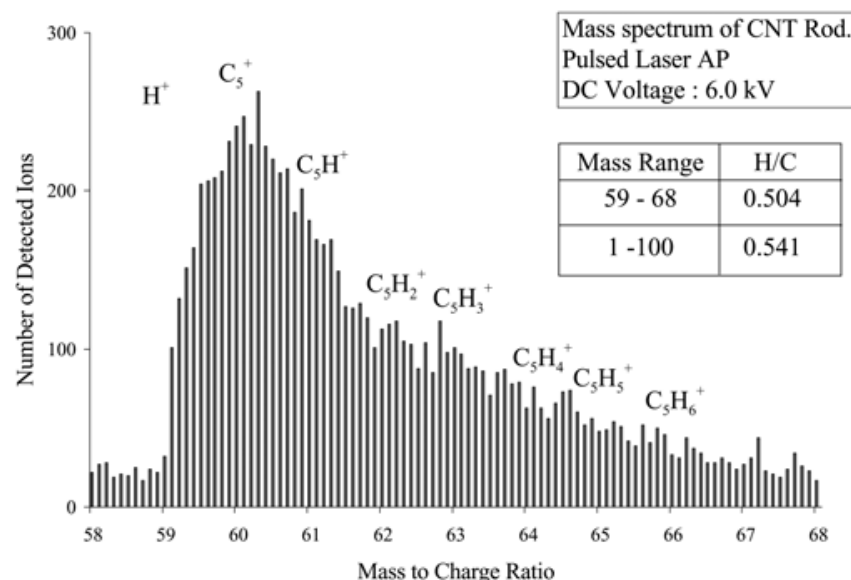

Fig. 1. Extended spectrum of CNT rod.

Table 2. Variation of $\mathrm{H}, \mathrm{C}$ and $\mathrm{O}$ concentration with depth (Clean surface) HF-treated Si $\mathrm{NH}_{4} \mathrm{~F}$-treated Si

\begin{tabular}{|l|l|l|l||l|l|l|l|}
\hline & $\mathrm{H}(\%)$ & $\mathrm{C} \mathrm{( \% )}$ & $\mathrm{O}(\%)$ & Number of ions & $\mathrm{H} \mathrm{( \% )}$ & $\mathrm{C}(\%)$ & $\mathrm{O}(\%)$ \\
\hline \hline Surface Layer & 24.2 & 14.4 & 0 & Surface Layer 1-1000 & 42.8 & 19.7 & 1.20 \\
\hline & & & & $1001-2000$ & 23.1 & 3.81 & 0.28 \\
\hline & & & & $2001-3000$ & 20.7 & 0.71 & 0 \\
\hline
\end{tabular}

Table 3. Variation of $\mathrm{H}, \mathrm{C}$ and $\mathrm{O}$ concentration with depth (Relatively contaminated surface) HF-treated Si $\mathrm{NH}_{4} \mathrm{~F}$-treated $\mathrm{Si}$

\begin{tabular}{|l|l|l|l||l|l|l|l|}
\hline Number of ions & $\mathrm{H}(\%)$ & $\mathrm{C}(\%)$ & $\mathrm{O}(\%)$ & Number of ions & $\mathrm{H}(\%)$ & $\mathrm{C}(\%)$ & $\mathrm{O}(\%)$ \\
\hline Surface layer 1-1000 & 42.8 & 19.7 & 1.2 & Surface layer 1-2000 & 35.0 & 18.8 & 1.11 \\
\hline $1001-4500$ & 23.1 & 3.81 & 0.28 & $2001-3600$ & 15.9 & 0.34 & 0.34 \\
\hline $4501-8000$ & 20.7 & 0.71 & 0 & $3601-5200$ & 18.8 & 0.30 & 0 \\
\hline & & & & $5201-6800$ & 18.8 & 0.31 & 0 \\
\hline
\end{tabular}



Fig. 2. Mass spectrum of clean Si.

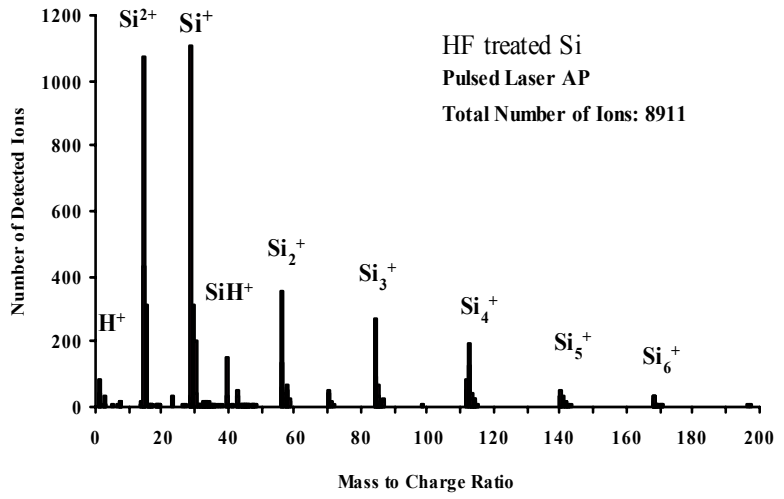

Fig. 3. Mass spectrum of relatively contaminated $\mathrm{Si}$. 